TRENDS IN HYDROZOAN BIOLOGY - IV. C.E. MILLS, F. BOERO, A. MIGOTTO and J.M. GILI (eds.)

\title{
Strobilation in a species of Bougainvillioidea (Cnidaria, Hydrozoa)*
}

\author{
GIORGIO BAVESTRELLO ${ }^{1}$, STEFANIA PUCE ${ }^{2}$, CARLO CERRANO² and \\ LORENZO SENES ${ }^{3}$
}

\begin{abstract}
${ }^{1}$ Istituto di Scienze del Mare dell'Università di Ancona, Via Brecce Bianche, I-60131 Ancona. Italy. ${ }^{2}$ Dipartimento per lo studio del Territorio e delle sue Risorse dell’Università di Genova, C. so Europa 26, I-16132 Genova. ${ }^{3}$ Acquario di Genova, Area Porto Antico, I-16100 Genova.
\end{abstract}

\begin{abstract}
SUMMARY: In november 1994 several specimens of an unknown hydroid were collected in a tank of the Genoa Aquarium (Italy). The polyps, characterised by filiform tentacles around a proboscis, displayed unusual asexual reproduction, leading to a linear chain of three elements (strobilation) joined by alternate oro-aboral polarity. This hydroid is very similar to another, unidentified hydroid collected in 1954 in San Francisco Bay. The hydroid of the Genoa Aquarium released free medusae characterised by four marginal tentacles, four radial canals and four oral tentacles around a tubular mouth. These features indicate that the species belongs to the superfamily Bougainvillioidea.
\end{abstract}

Key words: Bougainvillioidea, strobilation, asexual reproduction, polyp, medusa.

\section{INTRODUCTION}

In November 1954 Hand and Jones (1957) collected two live hydroid specimens from a core sample taken at 30 feet depth off Pt Richmond (San Francisco Bay, California). The bottom was composed of grey mud covered with about $5 \mathrm{~mm}$ of loose debris from which the hydroid was taken.

These hydroids, a single polyp and a pair of polyps united at their base, had filiform, very extensible tentacles arranged in a single whorl surrounding a proboscis. They were characterised by a peculiar asexual reproduction, leading to a linear chain of three elements (Fig. 1). Unfortunately all individuals died some months after the collection, and though more than 1200 core samples were taken

\footnotetext{
*Received March 20, 1999. Accepted May 3, 1999
}

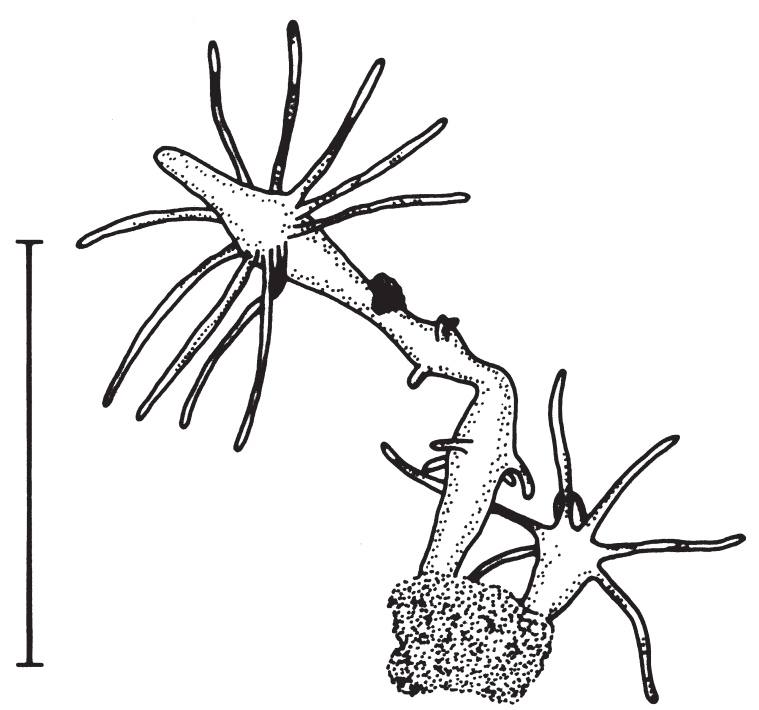

FIG. 1. - A triple and a solitary polyp as figured by Hand and Jones (1957). Scale bar $=1 \mathrm{~mm}$ 


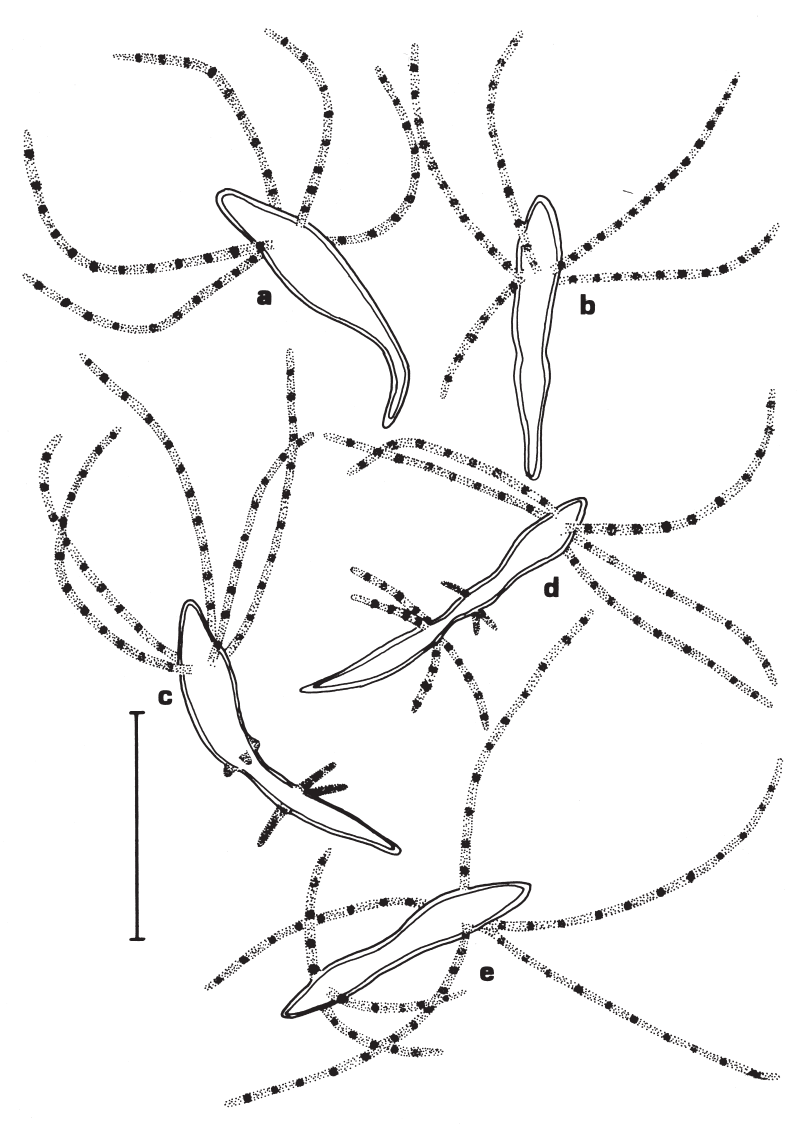

FIG. 2. - Different phases of asexual reproduction of the hydroid from the Genoa Aquarium. On the body of a solitary polyp (a), a constriction develops (b), two whorls of tentacles arise immediately above and below this narrowing, producing a chain of three elements (c) (d), fragmentation of a triple polyp, giving rise to a normal solitary polyp and a double one (e). Scale bar $=1 \mathrm{~mm}$

from the original area of collection, none has been found since (Hand and Jones, 1957).

Exactly forty years later, in November 1994, several specimens of a similar hydroid were taken from a tank of the Genoa Aquarium. We reared this hydroid and observed its morphology, asexual reproduction and release of medusae.

\section{RESULTS}

The morphology of the polyp varies with the reproductive phase. The solitary polyp consisted of a sub-cylindrical, naked body ending in a conical hypostome, surrounded by 4-5 filiform tentacles (Fig. 2a). The basal region was free and had no contact with the substratum, but was sometimes attached to particles of sand.

Asexual reproduction of the polyp started with the development of a constriction in the middle of the body (Fig. 2b), followed by the growth of two whorls of tentacles, one immediately above and one below this narrowing, resulting in a chain of three elements (Figs 2c, d, 3a). The hypostome of the first element was connected to the hypostome of the second element, whose opposite, aboral portion was attached to the aboral portion of the third. This chain had a free aboral part on one end and a free hypostome on the other. During this phase all the elements were able to feed. If Artemia nauplii were collected by the elements joined at the hypostome, their mouths might partially detach, become functional and re-fuse after the ingestion of the prey.

After some days these triple polyps fragmented and produced a normal, solitary polyp and a double one. The latter had a functional hypostome and a whorl of tentacles at each extremity (Figs. 2e, 3b). The solitary polyps constituted the reproductive individuals, while the double polyps generally remained unchanged in their condition. Perisarc structures were totally absent in each phase of the cycle. Under laboratory conditions, the sequence of the steps in this unusual asexual mode of reproduction was very constant.

Medusa buds were produced in verticils, 2-5 per polyp, during each step of the asexual reproductory process; the buds arose from the body of the initial hydranth of the chain, immediately under the tentacular whorl (Fig. 4a).

Newly released medusae were bell-shaped, $2 \mathrm{~mm}$ in diameter, with four radial canals, four tentacular bulbs with ocelli, and a circular canal. From each bulb a group of two tentacles arose. The manubrium was cylindrical with four unbranched oral tentacles around a simple, tubular mouth (Fig. 4b). After five

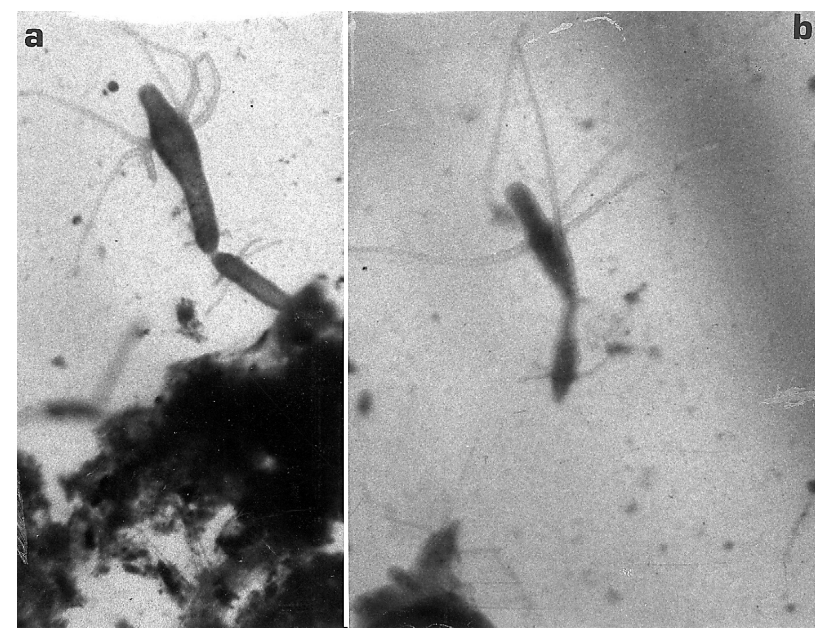

FIG. 3. - Photomicrographs of a chain of three elements, showing the whorls of tentacles (a) and of a double polyp floating in water 


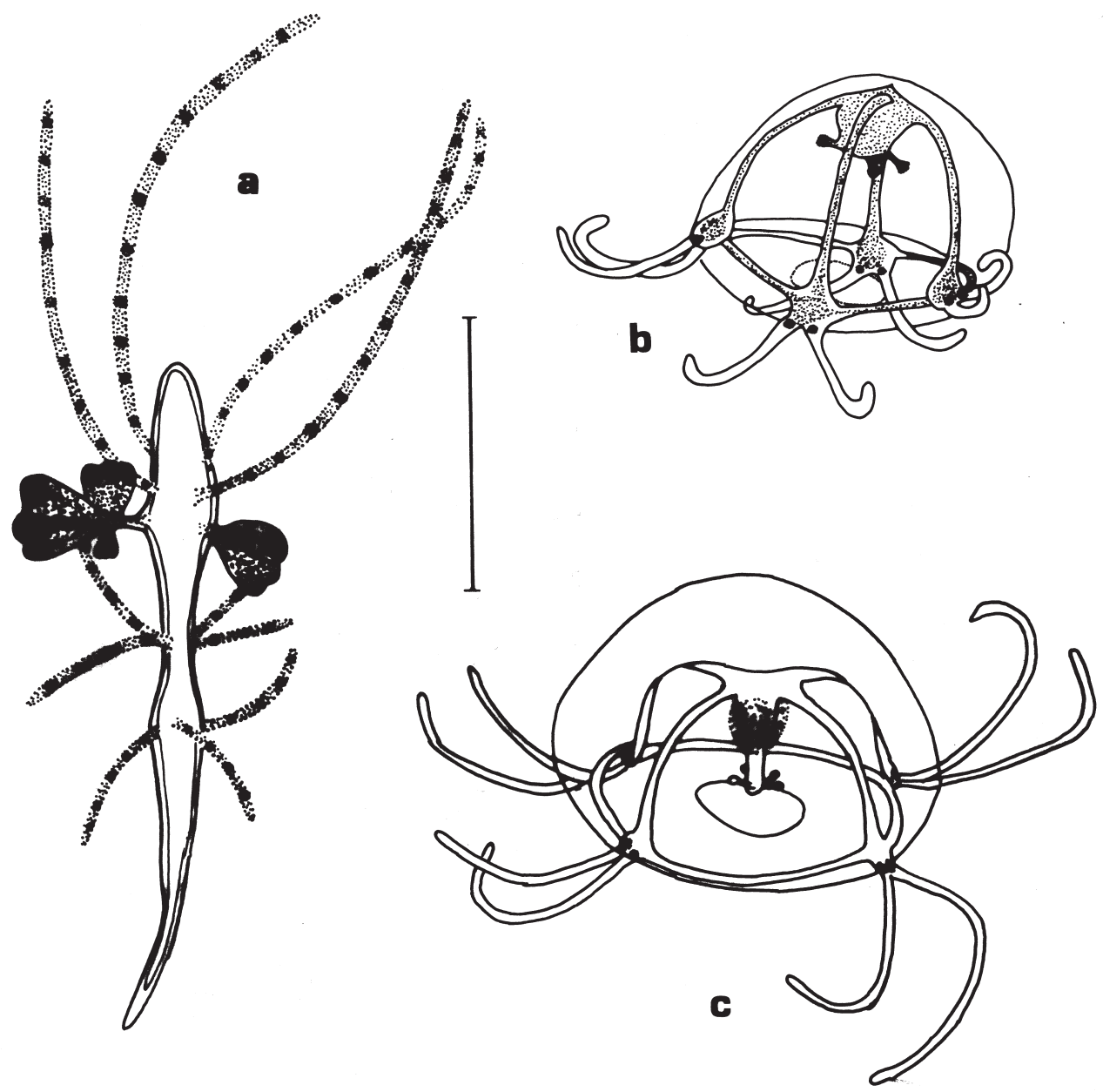

FIG. 4. - a, medusa buds on the body of a triple hydranth. $\mathrm{b}$, one-day-old medusa. c, five-day- old medusa. Scale bar $=1 \mathrm{~mm}$

days of rearing, gonads appeared on the manubrium (Fig. 4c).

The nematocysts were microbasic euryteles (9$10 \times 3 \mu \mathrm{m})$ and desmonemes $(4-5 \times 3-4 \mu \mathrm{m})$ in both the polyps and the medusae.

After two weeks of rearing the polyps showed a dramatic regression, producing sub-spherical masses of cells that remained in this condition for several months.

Under rearing conditions the polyps lived in the sediment or, under strong water movement, passively fluctuate in the water currents keeping their tentacles expanded.

\section{DISCUSSION}

The shape of the polyps and, particularly, their peculiar reproductive strategy indicate that the hydroid of the Genoa Aquarium and that recorded by Hand and Jones (1957) at Pt Richmond are close- ly related. Hand and Jones indicated a slightly different pattern of asexual reproduction, resulting in the production of two pairs of polyps. In the process of development described, adhesion of the polyps to bottom sediment is important for chain formation, whereas our specimens complete the entire reproductive cycle floating in the water without any contact with particles from the bottom (Fig. 3b).

Unfortunately, the dramatic degeneration of the polyps in culture did not allow us to preserve material for a formal species description. Nevertheless, our data give some indications concerning the systematic position of this hydroid. In fact, the features of the medusa and the nematocyst complement indicate that it is related to the superfamily Bougainvillioidea Petersen, 1979. The main features traditionally linking the species of this taxon are: (i) the absence of polymorphism; (ii) the presence of oral tentacles and a simple, tubular mouth in the medusae; (iii) gonophores arising directly from the hydrorhiza, the pedicels or specialised 
polyps. Our species does not share this last characteristic, producing medusa buds directly on the body of a normal gastrozooids as, however, also happens in the aberrant Bougainvilliidae genus Nemopsis (Nagao, 1964).

The main characteristic of this hydroid is its peculiar kind of asexual reproduction, producing new polyps by transverse fission along a linear axis instead of by lateral gemmulation. Cases of asexual reproduction by transverse fission are already known in some species of hydroids. Among thecate hydroids, free hydranths are produced only by Zelounies estrambordi Gravier-Bonnet, 1992 through a peculiar kind of autotomy, in which the polyp goes through a process of characteristic transformations before detachment from the original colony (Gravier-Bonnet, 1992). Among athecate hydroids, the first observation of transverse fission is that of "decapitation" in Moerisia lyonsi Boulenger, 1908, whose hydrants leave a "basal bulb" adhering to the substrate after the detachment of their apical portions (Ritchie, 1915). Other examples of "decapitation" are found in the free hydranths of Euphysa (Brinckmann-Voss, 1967), and in those of Ectopleura larynx (Ellis and Solander, 1786) (cf. Tardent, 1963, 1965; Mackie, 1966; Rungger, 1969, all as Tubularia larynx).

In our hydroids, however, transversal fission is preceded by the formation of a peculiar chain of three polyps. In the animal kingdom, asexual reproduction by means of a chain of elements produced along a linear axis is named strobilation and is present in several taxa such as: siphonophores, scyphozoans, polychaetes and tunicates. Although these groups do not show evident phylogenetic relationships, all the elements of the chain have the same polarity. Our hydroid, to the contrary, exhibits inversion in the oro-aboral axis in its chain. Another dissimilarity to strobilation in other animal taxa is the fact that, generally, the chains are composed of an undefined number of elements while in our hydroid the number of polyps, under normal conditions, is always three. Nevertheless, under condi- tions of stress, the chain never fragments and the number of polyps increases up to 14 (Hand and Jones, 1957).

In higher metazoans, the spatiotemporal development of morphological structures is regulated by homeobox genes. These genes are particularly involved in the repetition of metameric parts along an oro-aboral axis (Lawrence, 1992). Homeoboxes have also been observed in lower metazoans as such cnidarians (Schierwater et al., 1991) and sponges (e.g. Seimiya et al., 1997) but their meaning has been obscure until now. We hypothesise that the characteristic chain, with an inversion of polarity among its element as described here, may be controlled by these genetic structures.

\section{REFERENCES}

Brinckmann-Voss, A. - 1967. The hydroid of Vannuccia forbesi (Anthomedusae, Tubulariidae). Breviora, 263: 1-10.

Gravier-Bonnet, N. - 1992. Cloning and dispersal by buoyant autotomised hydranths of a Thecate hydroid (Cnidaria; Hydrozoa). Sci. Mar., 56 (2-3): 229-236.

Hand, C. and M.L. Jones. - 1957. An example of reversal of polarity during asexual reproduction of a hydroid. Biol. Bull., 112(3): 349-357.

Lawrence, P.A. - 1992. The making of a fly: the genetics of animal design. Blackwell Scientific, Oxford.

Mackie, G.O. - 1966. Growth of the hydroid Tubularia in culture. In: W. J. Rees (eds.): The Cnidaria and their Evolution. pp. 397-412. Academic Press. New York.

Nagao, Z. - 1964. The life cycle of the hydromedusa Nemopsis dofleini Maas, with a supplementary note on the life history of Bougainvillia superciliaris (L. Agassiz). Annotnes Zool. Jap., 37: 153-162.

Petersen, K.W. - 1979. Development of coloniality in Hydrozoa. In: G. Larwood and B.R. Rosen (eds.), Biology and systematics of colonial organisms. Systematics Association special volumes 11, pp. 105-139. Academic Press, London and New York.

Ritchie, J. - 1915. The hydroids of the Indian Museum. II - Annulella gemmata, a new and remarkable brackish-water hydroid. Rec. Ind. Mus., 11: 541-568.

Rungger, D. - 1969. Autotomy in Tubularia crocea and its ecological and physiological significance. Pubbl. Staz. Zool. Nap., 37: 95-139.

Schierwater, B., M. Murtha, M. Dick, F.H. Ruddle and L.W. Buss. - 1991. Homeoboxes in Cnidarians. J. exp. Zool., 260: 413-416.

Seimiya, M., H. Ishiguro, K. Miura, Y. Watanabe and Y. Kurosawa. - 1997. Homeobox-containing genes in the most primitive Metazoa, the sponges. Eur. J. Biochem., 221: 219-225.

Tardent, P. - 1963. Regeneration in the Hydrozoa. Biol. Rev., 38 : 293-333.

Tardent, P. - 1965. Ecological aspects of the morphodynamics of some Hydrozoa. Amer. Zool., 5: 525-529. 